\title{
EDUCAÇÃO E SAÚDE NA MODERNIDADE E PÓS-MODERNIDADE: UM RESGATE DA HISTÓRIA.
}

\section{EDUCATION AND HEALTH AT MODERNITY AND AFTER-MODERNITY: A HISTORY RANSOM.}

\author{
Neuza Mainardi ${ }^{1}$ \\ Isabel Maria Teixeira Bicudo Pereira ${ }^{2}$ \\ Maria Cecília Focesi Pelicioni ${ }^{3}$
}

O presente estudo faz um resgate histórico do caminhar das escolas públicas e particulares de ensino fundamental e da saúde na modernidade e pós- modernidade, no Brasil, perpassando todo o século XX. Mostra a evolução do ensino tradicional e do movimento escolanovista até as propostas educacionais para os dias atuais, assim como a evolução do conceito biomédico da saúde entendendo-a como qualidade de vida.

Palavras-chave: educação em saúde, promoção da saúde, escolarização, saúde.

This study comments a historical way of official and particular fundamental school and the health, at modernity and after-modernity in Brazil, on the twentieth century. Show the evolution of traditional education to a new schooling movement until the educational proposal on actuality, how 's been the evolution of the biomedical health concept to another more positive, that of the quality of life.

Key-words: Health education, Health promotion, schooling, health

\section{INTRODUÇÃO}

Sendo a educação e a saúde direitos universais e de todo o cidadão brasileiro, conforme prescreve a Carta Magna de 1988 em vigor no país, a escola, assim como outras instituições da sociedade, tem o dever de contribuir da melhor forma possível para que a saúde seja da melhor qualidade. Conforme o acordado nas Conferências Internacionais para a Promoção da Saúde que aconteceram desde 1986, em diferentes países e com a participação do Brasil, todos os segmentos da sociedade devem ser envolvidos, sejam elas do setor público ou privado, num trabalho individual e coletivo em prol da promoção da saúde.

\footnotetext{
${ }^{1}$ Especialista em Educação, membro do Grupo de Pesquisa em Administração Escolar - DEPAE Faculdade de Educação da USP - nmainardi@usp.br

2 Professora e doutora em Saúde Pública, Faculdade de Saúde Pública da Universidade de São Paulo - claianny@usp.br

${ }^{3}$ Doutora e livre docente, Faculdade de Saúde Pública da Universidade de São Paulo - tatim@usp.br
} 


\section{MODERNIDADE}

\subsection{A PRIMEIRA METADE DO SÉCULO XX ...}

No Brasil, a educação e a saúde sempre caminharam lado a lado. No início do século $\mathrm{XX}$ a escola era praticamente uma extensão do lar e privilégio de meninos de famílias tradicionais que viviam em cidades, onde se construíam os primeiros prédios de escolas públicas. Não se considerava a escola uma necessidade a todos os grupos sociais e o ensino era mecânico. Após a primeira década, já era comum a inclusão também de meninas que tivessem condições de ir ao centro da cidade para os estudos. Eram raros os povoados rurais que podiam contar com a boa vontade de algum professor que para lá se dirigisse num trabalho de verdadeira vocação, ensinando às crianças as primeiras letras, pequenos cálculos, noções de cuidados e boas maneiras, segundo os padrões vigentes na época, recebendo por pagamento: ovos, galinhas, frutas e outros produtos que as famílias das crianças gentilmente lhes ofertavam.

Nessa época eram comuns as mortes em tenra idade por doenças infecciosas, uma vez que, antes da década de 20, não existiam antibióticos .

No ensino particular já se contava com o modelo de educação americana desde 1881, quando vieram os metodistas ao Brasil, instalando-se em Piracicaba, município distante cerca de $160 \mathrm{Km}$ da capital de São Paulo e onde fundaram o Colégio Piracicabano, ainda existente, para alunos de ambos os sexos, dando origem à atual Universidade Metodista de Piracicaba - UNIMEP. Mostraram a importância das relações humanas, da música e do esporte, construindo uma piscina para uso dos alunos, uma iniciativa arrojada para a época. É notória sua preocupação com a saúde física e mental.

Para os meninos que buscavam o ensino particular, havia no país, desde 1883, a educação européia, oferecida pelo Colégio Salesiano Dom Bosco, dirigido por padres católicos, que buscavam também propiciar a saúde física, mental e social e onde o esporte era bastante enfatizado sempre com a supervisão de um educador. Os salesianos se instalaram inicialmente em Niterói- Rio de Janeiro, com objetivo de educar a comunidade carente beneficiada pela Lei do Ventre-Livre, evangelizando-a. A pedagogia de Dom Bosco considera a atividade educativa como vitalmente ligada à evolução do sujeito, desenvolvendo valores considerados fundamentais: verdade, liberdade, amor, trabalho, justiça, solidariedade, participação, dignidade (Villanueva, 2008). 
Em 1922, vieram de Graz (Áustria) ao Brasil, as irmãs franciscanas, católicas, instalando-se também na cidade paulista de Piracicaba, onde criaram o Instituto Baronesa de Rezende, também existente até hoje, oferecendo educação infantil e básica : ensino fundamental e médio. Naqueles tempos ofereciam somente educação primária (portanto de $1^{\underline{a}}$ a $4^{\underline{a}}$ séries) para meninas. Vieram com idéias inovadoras, influenciadas pela pedagogia de Kerschensteiner, pedagogo que havia introduzido trabalhos manuais nas escolas da Alemanha, oferecendo oficinas para os meninos e aulas de culinária para as meninas. Criaram naquela cidade o primeiro Curso de Educação Alimentar do Brasil, onde ensinavam desde as escolhas dos alimentos, até a montagem conveniente de um cardápio diário equilibrado, com aulas teóricas e práticas de preparo dos alimentos e cálculos das despesas. Era uma importante contribuição à saúde. Passados alguns anos, incluíram também no Instituto, aulas de bordado, piano, acordeão, violino e outros instrumentos musicais, abrindo um Conservatório Dramático e Musical na cidade. Portanto, além das noções de cuidados pessoais, do ambiente, da boa alimentação e dos bons costumes ministrados nas aulas comuns, havia notória preocupação com a saúde mental. As moças que frequentavam, à parte, o Curso de Arte Culinária recebiam ainda noções de enfermagem e de como cuidar de bebês e da arrumação da casa, numa demonstração clara de que a mulher era preparada para o casamento e para cuidar do lar (MAINARDI, 2005).

Em 1890, a Escola Normal da Capital de São Paulo que era dirigida por Caetano de Campos, já contava com professoras especializadas nos Estados Unidos quanto as idéias de educação renovada pregadas por John Dewey. Certamente aí foi o início do movimento conhecido por Escola Nova no Brasil, em escolas públicas.

Com o advento da primeira Guerra Mundial (1914-1918) houve um grande desequilíbrio social, cultural, econômico e político no país. Era preciso rever os princípios da educação e suas instituições, para que visassem a preservação da paz..

O pilar de sustentação da ciência e da sociedade era o da regulação, da ordem e da lógica formal. As estratégias eram passadas de geração a geração e os resultados eram absolutamente previsíveis, salvo raríssimas exceções, que geralmente eram tidas como perturbadoras da ordem, por melhor intencionadas que fossem.

Em São Paulo, Piracicaba foi privilegiada no setor educacional, o que a tornou conhecida como a "Atenas Paulista" na época.. Além dessas escolas com pedagogia 
americana e européia, na primeira década do século XX já contava com uma Escola Normal oficial para formação de professores ( hoje Escola Estadual "Sud Menucci") e com um Curso Superior de Agricultura, a Escola Superior de Agricultura Luiz de Queiroz - Universidade de São Paulo (USP).

O ensino era tradicional nas escolas públicas brasileiras estando longe de aceitar uma relação dialética entre professores e alunos. Aos estudantes cabia apenas entender as exposições dos mestres, sem questioná-las, muitas vezes precisando decorar o que lhes era transmitido e demonstrar o que tinham compreendido em provas escritas e arguições orais.

Tais escolas costumavam distribuir folhetos que orientavam a população sobre questões de higiene e saúde.

O movimento da Escola Nova começou em São Paulo, em 1920, quando a Escola Experimental Rio Branco comandada por Sampaio Dória, propôs que os alunos fossem mais ativos, mais autônomos, mais considerados quanto aos seus interesses de aprendizagem, quanto aos seus sentimentos, quanto a sua individualidade, quanto à sua interação social.

No Ceará, o responsável pela reforma educacional foi Lourenço Filho, em 1922. Em 1924, o movimento continuou na Bahia com Anísio Teixeira, em 1925 em Pernambuco com Carneiro Leão, em 1927, no Paraná com Lisímaco da Costa e, em 1927, no Rio de Janeiro, com Fernando Azevedo . Neste último Estado houve uma inovação: foi criado o Círculo de Mães, visando educar os alunos individualmente e também seus pais. Em 1928 a reforma foi iniciada em Minas Gerais com Francisco Campos; após 1930 a Escola Nova começou também no Rio Grande do Sul (Soares e Silva, 2007)

Em 1932 as convicções dos escolanovistas foram divulgadas através do Manifesto dos Pioneiros da Escola Nova, com teses inspiradas na obra do americano John Dewey.

Ainda na década de 30, em São Paulo, no município de Cruzeiro, houve um trabalho de verdadeira educação funcional com Álvaro Neiva; o Instituto Cruzeiro mantinha internato e externato, seguindo programas do padrão federal, com associações, grêmios, cooperativas e oficinas, uma escola ativa, com alunos solidários e participantes (LOURENÇO FILHO,1978).

Por evidente necessidade, em 1935 foi criado o Ministério dos Negócios da Educação e da Saúde 
A biologia, a psicologia e as ciências sociais contribuíram decisivamente para uma postura técnica por parte dos educadores. Foi a partir de resultados de pesquisa nestas áreas que se passou a considerar a importância de se conhecer o aluno para auxiliá-lo a atingir os objetivos. Os princípios empíricos da escola tradicional foram substituídos por outros de base técnica. Como conseqüência surgiu a necessidade da administração escolar.

\subsection{O PERÍODO PÓS- 2ª GUERRA MUNDIAL}

Após a segunda guerra mundial (1939-1945) grandes transformações aconteceram, nos mais diferentes setores, no Brasil e no mundo. Foi criada a ONUOrganização das Nações Unidas e proclamados os Direitos Humanos Universais.

"O rápido desenvolvimento da ciência e tecnologia e a ampliação do processo de comunicação, comércio e inter-relação entre os países acarretaram especialmente para os países em desenvolvimento, consequências e impactos em diversas dimensões das suas realidades" (LEFÈVRE e LEFÈVRE, 2004).

Acelerou-se o desenvolvimento industrial e a escola passou a ser uma necessidade também para a classe trabalhadora. Foram criados o SESI, o SENAI e o SENAC, que ofereciam cursos rápidos de Educação Alimentar, Noções de Enfermagem, de Higiene, de Costura e informações referentes à Indústria e ao Comercio. Em 1948 foram criados Cursos de Alfabetização de Adultos.

$\mathrm{Na}$ década de 50 as escolas brasileiras começaram servir a merenda escolar aos alunos; as do Estado de São Paulo contavam com uma educadora sanitária que, num trabalho preventivo, examinava cada criança, orientando a família em casos de eventual necessidade de tratamento; havia também um (a) dentista para atendimento das crianças. Esses profissionais costumavam fazer palestras de orientação quanto à saúde e higiene do corpo e bucal. No dia-a-dia das salas de aula, outras questões de saúde eram tratadas pelos professores, segundo as possibilidades de compreensão das crianças. Avaliações oculares, usando o Teste de Snellem, também existiam e encaminhamentos para o oftalmologista eram feitos, quando necessário.

Em 1961 entrou em vigor a Lei Federal 4024, a primeira de diretrizes e bases para a educação nacional. Era de caráter seletivo e apenas os que demonstrassem melhores condições intelectuais, em prova escrita de considerável dificuldade, podiam prosseguir estudos além do $4^{\circ}$ ano do curso primário e ingressar no ginásio, composto de mais 4 anos ; havia o colegial de 3 anos para os que concluíssem o 
ginásio. Essa Lei primava pela qualidade, pelo desenvolvimento de uma cultura geral no indivíduo, preocupando-se com os fins, com os ideais a serem alcançados. Previa aulas semanais sobre Noções de Primeiros Socorros e/ou Educação Alimentar e/ou Trabalhos Manuais e Costura, nas escolas públicas. Era necessário demonstrar muita competência para prosseguir os estudos. Os que não obtinham aprovação nos exames públicos de admissão ao ginásio, buscavam as escolas particulares, tidas como de menor qualidade.

No Ministério da Saúde, foram criados órgãos para combate às endemias e órgãos normativos para ações sanitárias educativas, orientadas para um melhor cuidado de si e do outro, numa busca por melhor qualidade de vida.

Em 1960, com a Lei Orgânica da Previdência Social, os Institutos de Aposentadorias e Pensões geridos por sindicatos foram unificados e o regime de atenção à saúde passou a ser o mesmo para todos os trabalhadores regidos pela Consolidação das Leis do Trabalho . Em 1963, foi criado o FUNRURAL para atender os camponeses e em 1967, o Instituto Nacional de Previdência Social (INPS), onde a demanda era maior que a oferta, cabendo ao governo pagar a rede privada para atender às necessidades da população, na área da saúde.

Visando ampliar a oferta de escolarização obrigatória para 8 anos, em 1971, foi promulgada e entrou em vigor a Lei 5692, com novas diretrizes, instituindo o primeiro grau de 8 anos e o segundo de três, sendo que Programas de Saúde passaram a integrar o currículo obrigatório. Foram priorizados 0 ensino profissionalizante e as

estratégias de ensino, ou seja, os aspectos metodológicos. Com a grande expansão quantitativa da rede, começa a decadência da escola pública, pois além das questões políticas, fator precípuo, faltavam profissionais habilitados para assumir as aulas, que passaram a ser ministradas por dentistas, engenheiros, advogados, contratados em caráter temporário ou excepcional, emergencial, o que continua até os dias atuais.

Nessa época criaram-se muitas escolas particulares, com objetivo de oferecer às classes privilegiadas, um ensino de melhor qualidade. Houve uma inversão de valores! A classe média e a alta lotaram estes estabelecimentos, sem analisar que, muitas vezes, eram dirigidos pelos seus proprietários: engenheiros agrônomos, advogados, comerciantes, pessoal não habilitado, que tinha percebido ser uma oportunidade rentável. Cada escola se esforçava para publicar na imprensa a quantidade de alunos aprovados em vestibular para o ensino superior, visando 
motivar a escolha do estabelecimento por novos interessados; a formação de valores, atitudes, habilidades parece não terem sido mais levadas em grande consideração. Pode ter sido esse o início da visão da escola como simples informadora, uma organização prestadora de serviços ao invés de instituição formadora.

Em 1973, foi criado pelo Ministério da Saúde, o Programa Nacional de Imunizações segundo o qual todas as crianças deveriam ser, obrigatoriamente, vacinadas, obedecendo calendário oficial .

Em 1974, o governo militar criou o Fundo de Apoio ao Desenvolvimento Social (FAS), emprestando dinheiro para ampliação de hospitais particulares que atendiam à demanda encaminhada pelo governo. Tudo foi ficando mais complexo e em 1978, foi criado o Instituto Nacional de Assistência Médica da Previdência Social (INAMPS). De 1964 a 1984 o número de leitos privados cresceu em 500\%. Entretanto, poucas medidas de prevenção e sanitárias foram tomadas; a mais importante foi a criação da SUCAM -

Superintendência de Campanhas da Saúde Pública, órgão diretamente ligado ao Ministério da Saúde, com a preocupação de erradicar e controlar endemias. Foi criado também o CONASP - Conselho Consultivo de Administração de Saúde Previdenciária., composto por representantes de cada Ministério, das Confederações Nacionais dos três setores da economia: agropecuária, indústria e comércio e dos trabalhadores que, reunindo-se uma vez por mês no Ministério da Previdência e Assistência Social, objetivavam opinar sobre a organização e o aperfeiçoamento da Assistência Médica e Previdência Social.

Com o fim do regime militar surgiram outros órgãos que apresentaram uma abertura de canal de participação da sociedade civil nos assuntos da Saúde como, por exemplo, o Conselho Nacional dos Secretários de Estado da Saúde (CONASS) e - Conselho Nacional dos Secretários Municipais de Saúde (CONASEMS). O CONASS tem se caracterizado pela renovação e fortalecimento do seu papel político a partir da construção de consensos entre os Secretários e uma grande necessidade de comunicação entre os seus pares e entre esses e a sociedade. Quanto ao CONASEMS, nasceu de um movimento social em prol da saúde pública e se legitimou como força política que assumiu a missão de agregar e de representar o conjunto de todas as secretarias municipais de saúde do país; sua tarefa tem sido "promover e consolidar um novo modelo de gestão pública de saúde alicerçado em conceitos como descentralização e municipalização" (Brasil - RIPSA). 
O setor privado criou Convênios para atendimento médico. Surgiram a medicina de grupos, cooperativas médicas, autogestão, seguro-saúde, planos de administração. A classe média aderiu imediatamente, respondendo contra as falhas da saúde pública e com isso, os planos de saúde cresceram vertiginosamente.

O modelo estabelecido era o da medicina curativa e conseguir ter saúde conforme conceituava a Organização Mundial de Saúde....um completo estado de bem estar físico, mental e social" ... era um ideal inatingível.

\section{PÓS-MODERNIDADE}

Há um consenso de que os anos 80 "apontaram para o limiar de uma nova era, que conduz a humanidade para além da modernidade... a pós-modernidade, uma sociedade com ênfase na informação e no conhecimento" (LEFÈVRE e LEFÈVRE, 2004).

As mudanças em todos os sentidos, e cada vez mais velozes, passaram a ser a constante nas sociedades capitalistas contemporâneas, causando impactos, mudando os paradigmas e projetos. Nesse mundo globalizado as pessoas, cada vez mais, se unem por interesses comuns, independentemente do espaço geográfico onde vivem, pois muito pode ser resolvido pela internet. É um tempo onde tem valor a criatividade, a emancipação dos sujeitos e onde o problema da sobrevivência da vida na Terra se coloca de maneira crucial. Cresce a consciência da descontinuidade, da necessidade do diálogo, da complexidade da vida.

As pessoas precisam se tornar sujeitos responsáveis pela própria vida (MAINARDI e PEREIRA, 2007).

Ocorre que a participação social promovida pelas instituições é questionável, pois essa participação enfrenta dificuldades de caráter político, cultural e econômico (VALLA, 1998; ZAKUS e LYRACK, 1998; DIAS, 1998; STONE, 1992; WOELK, 1992). Nem sempre a população tem informações sobre os seus direitos em saúde e o acesso a essa informação é básico para a participação no sistema de saúde e democratização dos serviços (KLEIN, 1984)

Apenas uma parte da população conhece a existência e utiliza superficialmente, os mecanismos institucionais de participação coletivos (ARSTEIN, 1969).

A reforma do setor saúde no Brasil contempla como eixo fundamental a democratização dos serviços de saúde através do exercício do controle social sobre o sistema de saúde, hoje unificado e claramente definido na Constituição Federal de 
1988, em vigor , nas Leis Federais 8080/90 e 8142/90 e em outras legislações. A Lei 8080 dispõe sobre as condições para a promoção, proteção e recuperação da saúde, a organização e funcionamento dos serviços correspondentes e dá outras providências e a Lei 8142 dispõe sobre a participação da comunidade na gestão do SUS e sobre as transferências intergovernamentais de recursos financeiros na área da saúde e dá outras providências.

Foram realizadas no Brasil, treze Conferências Nacionais para se discutir saúde, estabelecendo - se inclusive mecanismos para participação individual dos cidadãos: disque saúde, caixa de queixas e sugestões, ouvidores em saúde.

A 8 a Conferência Nacional em Saúde (CNS), em 1986, teve como tema "Democracia é Saúde" e constituiu-se "em fórum de luta pela descentralização do sistema de saúde e pela implantação de políticas sociais que defendessem e cuidassem da vida". Era um momento chave do Movimento da Reforma Sanitária Brasileira e da afirmação da impossibilidade de dissociar a garantia da saúde como direito social irrevogável, da garantia dos demais direitos humanos e de cidadania. (Gov.Minas Gerais, 2006). As Conferências foram ampliando o conceito de saúde, cada vez mais entendido como resultante das condições de vida.

Em 1986, aconteceu um evento que veio mudar totalmente o conceito de saúde no mundo, apontando para horizontes mais amplos também para a área educacional. Foi realizada em Ottawa (Canadá) a I Conferência Internacional para a Promoção da Saúde, onde se discutiu principalmente as necessidades em saúde nos países industrializados. Na Carta de Otawa, a saúde foi apresentada como um conceito positivo, como um recurso para a vida, para o desenvolvimento pessoal, econômico e social; a qualidade de vida como um objetivo a ser atingido, pressupondo, para isto, a promoção de várias políticas públicas para a paz, habitação, educação, alimentação, renda, ecossistema estável , tão necessários em âmbito nacional e internacional.

Seguiram-se outros eventos internacionais e o Brasil se fez presente, assinando compromisso com as cartas resultantes. Em 1988 ocorreu a II Conferência Internacional de Promoção da Saúde em Adelaide (Austrália), onde se discutiram Políticas Públicas voltadas para a saúde, considerada um direito humano fundamental e um sólido investimento social. A Conferência de Adelaide mostrou que as políticas públicas de todos os setores do governo influem nos determinantes da saúde e podem reduzir iniquidades sociais. (WESTPHAL, 2006). 
Neste mesmo ano de 1988 foi promulgada a nova Constituição Brasileira, criando o Sistema Único de Saúde - SUS, que garantiu a todo brasileiro, o acesso universal e igualitário a ações e serviços para promoção, proteção e recuperação da saúde. Assim mesmo, com todas as dificuldades em sua implantação, trata-se de um marco muito importante, que veio favorecer de maneira ímpar toda a sociedade.

Aconteceu em 1991, em Sundsvall (Suécia), a III Conferência Internacional de Promoção da Saúde; o foco foi o desenvolvimento sustentável; ambiente e saúde são vistos como interdependentes e inseparáveis. Considerou-se que alianças deveriam ser concretizadas para assegurar acesso igualitário a ambientes favoráveis à saúde.

Em 1992, foi realizada em Santa Fé de Bogotá (Colômbia) a I Conferência da América Latina para a Promoção da Saúde. Saúde foi enfocada como responsabilidade de cada indivíduo, diminuindo, nesse contexto, a responsabilidade do Estado. A iniquidade foi o centro das discussões. Pela primeira vez a responsabilidade social foi passada, em parte, para as empresas particulares. Foi enfatizada a relação mútua entre desenvolvimento e saúde e a promoção da saúde vista como promoção social. A solidariedade e a equidade social passaram a ser vistas como condições indispensáveis para o desenvolvimento (WESTPHAL, 2006). Em Bogotá foi planejada a II Conferência Mundial para o Meio Ambiente e o Desenvolvimento - conhecida como ECO 92, ou Rio 92, realizada no Brasil, no Rio de Janeiro, quando foi consagrado o conceito de desenvolvimento sustentável.

Em dezembro de 1996, foi promulgada a Lei Federal 9394, com novas diretrizes e bases da educação nacional, com a Educação Básica compreendendo o Ensino Fundamental e o Médio. Hilsdorff, 2003 mostrou que a nova Lei, de fundo conservador, propõe algumas mudanças para que " o capitalismo se voltasse aos direitos sociais e à abertura do sistema educacional." Fora derrotada no Congresso, uma proposta educacional transformadora, encabeçada por entidades e associações educacionais que queriam um sistema econômico distributivo, uma escola pública voltada para as transformações sociais e uma democracia de massas.

Em 1997 aconteceu a IV Conferência Internacional para a Promoção da Saúde em Jacarta (Indonésia), onde se discutiu a Promoção da Saúde no Século XXI.; considerou-se que a saúde devesse ser efetuada pelo povo e com o povo, através do aumento de investimentos e expansão de parcerias com o setor privado. 
Enfatizou-se a importância do empoderamento ${ }^{4}$ por parte da sociedade (WESTPHAL, 2006).

"O empoderamento e a participação ativa da população preconizada pelo paradigma da Promoção da Saúde serão viabilizados por meio da educação em saúde, enquanto processo político de formação para a cidadania ativa, preparandose os indivíduos e/ou grupos para assumirem o controle e a responsabilidade sobre sua própria saúde, entre outros objetivos." (PELICIONI e PELICIONI,2007).

No ano 2000, ocorreu a V Conferência Internacional para a Promoção da Saúde no México, onde a saúde buscou maior equidade. Consideraram que deveria haver maior investimento, principalmente na educação, para que as ações desenvolvidas pela sociedade, a nível local, regional e nacional, pudessem reverter a favor da saúde.

Após a participação em eventos internacionais, cada país deveria organizar outros, bem coordenados, para discutir e repassar as conclusões, reavaliar a sua situação particular no setor, elaborar um planejamento estratégico e agir em favor da população. "Para se intervir numa realidade e obter mudanças desejáveis, faz-se necessário o planejamento estratégico, ou seja, planejar especificamente para enfrentar determinados problemas, com determinados recursos" (CASTRO e LEFÉVRE, 2004). Não é o que vem ocorrendo, tanto é que por esse motivo,

\footnotetext{
${ }^{4}$ Empowerment ou empoderamento é o processo de ação social de indivíduos e grupos comunitários para aumentar o controle sobre a vida e facilitar transformações ao nível individual e social (Wallerstein, 1992). Neste mesmo ano de 1997, no Brasil, o Ministério da Educação e Cultura e do Desporto - (MEC), por meio de sua Secretaria Nacional de Ensino Fundamental, apresentou os Parâmetros Curriculares Nacionais para serem implementados em todo o país. Estabeleceu ainda temas transversais que deveriam ser trabalhados por todos os professores, das diferentes disciplinas, permeando todo o currículo: Saúde, Ética, Orientação Sexual, Pluralidade Cultural, Educação e Consumo e Educação Ambiental. Tais temas são interligados e se fossem bem trabalhados em sala de aula, poderiam contribuir muito para a saúde e cidadania consciente, além de contribuir para o atendimento das necessidades específicas da realidade onde a escola estivesse inserida (MAINARDI e PEREIRA, 2007). Foi um marco importante para a educação nacional, mas faltou competência técnica dos educadores que atuam nas bases, para associação da teoria à prática; possivelmente as orientações não foram suficientes e adequadas e tudo parece ter caminhado muito pouco e em outros rumos que não os propostos pela Secretaria Nacional de Educação. Muitos professores tentaram trabalhar tais temas de forma fragmentada como conteúdos e não como vivência real, de forma contextualizada, independentemente do cargo que o profissional estivesse ocupando. Entretanto a legislação está em pleno vigor. Estes temas visam possibilitar uma escola voltada para a construção de cidadãos emancipados, uma escola que amplie e aprofunde um debate educacional envolvendo os pais dos alunos, as forças políticas e a sociedade, uma escola em que os docentes e os especialistas da educação reflitam sobre a prática pedagógica dando origem a uma transformação positiva no sistema educativo brasileiro. (MAINARDI e PIPITONE 2007). A competência técnica dos profissionais da educação é condição primordial para o sucesso de um trabalho dessa envergadura, pois esse entendimento faz toda a diferença; o conviver com situações cotidianas considerando o valor das pessoas próximas, e não apenas o seu valor como ser humano individual, favorece a formação de cabeças que pensam de forma coletiva, solidária, crítica, atentas à realidade, que poderá ser transformada para melhor pela atuação consciente das pessoas que passam não só a cumprir seus deveres, mas também a exigir seus direitos em quaisquer setores.
} 
deixaram de convidar os Srs Ministros da Saúde para a VI Conferência Internacional que aconteceu em 2005 em Bangkoc na Tailândia, com o tema: "Políticas e Parcerias para a Saúde: procurando interferir nos determinantes sociais da saúde". As discussões partiram do princípio que a saúde é influenciada pela globalização, pelo aumento crescente das desigualdades, pelos novos padrões de comunicação e consumo, pela crescente urbanização. Os participantes concluíram que há necessidade de se advogar pela saúde a favor dos direitos humanos e da solidariedade e de se investir em políticas públicas sustentáveis, em práticas de promoção da saúde, em construção de parcerias e alianças entre os setores públicos, privados, organizações não governamentais e sociedade civil para consecução dos objetivos de melhoria da qualidade de vida e saúde.

Vive-se hoje, um momento de transição epidemiológica: diminuiu consideravelmente a incidência de doenças infecto-contagiosas e aumentou a de doenças crônico-degenerativas; também presencia-se o ressurgir de doenças já tidas como controladas: tuberculose, hanseníase, febre amarela, dengue...

No Brasil, o Ministério da Saúde, o Conselho Nacional de Saúde e a Comissão Intergestora Tripartite apresentaram a Carta dos Direitos dos usuários do SUS e convidaram todos os gestores, profissionais de saúde, organizações civis, instituições e pessoas interessadas para que promovam o respeito a estes direitos $\mathrm{e}$ assegurem seu reconhecimento efetivo e sua aplicação. Essa carta foi aprovada pelo Ministério da Saúde pela Portaria 675/2006 tendo como princípios:

"I- todo cidadão tem direito ao acesso ordenado e organizado aos sistemas de saúde; II- todo cidadão tem direito a tratamento adequado e efetivo para seu problema; III- todo cidadão tem direito ao atendimento humanizado, acolhedor e livre de qualquer discriminação; IV- todo cidadão tem direito a atendimento que respeite sua pessoa, seus valores e seus direitos; $V$ - todo cidadão também tem responsabilidades para que seu tratamento aconteça da forma adequada; e VI- todo cidadão tem direito ao comprometimento dos gestores da saúde para que os princípios anteriores sejam cumpridos " (BRASIL, 2006).

Em 2006 foi firmado o Pacto pela Saúde objetivando contribuir para a consolidação do SUS; definiu-se então prioridades articuladas e integradas nos três componentes: Pacto pela Vida, Pacto em Defesa do SUS e Pacto de Gestão do SUS.

Outros eventos, em diferentes níveis também se realizaram para se pensar educação. Percebe-se que há teorizações de alto nível, porém poucos avanços são 
observados na prática. A escola brasileira "passa longe dos interesses dos alunos, fala uma língua desatualizada e reproduz o status quo." A criança é considerada incapaz e não é ouvida . O ideal de que a construção do ser humano fosse o projeto da escola não é contemplado (BOLEIZ JUNIOR, 2008).

É imprescindível que o professor conheça bem seus alunos para que possa planejar estrategicamente o seu trabalho de intervenção, de forma a produzir bons resultados. Qualquer intervenção só poderá ser bem sucedida se bem planejada. Educação é ação intencional.

Há que se admitir que o novo pilar de sustentação social e científica é o da emancipação, que valoriza sujeitos pensantes, atuantes, progressistas, autônomos. Nada é totalmente previsível. E essas mudanças, com as novas tecnologias, são cada vez mais rápidas!

As escolas precisam contribuir para a formação dos alunos neste sentido; os professores devem estimular a criatividade e estilos de vida saudáveis em toda a comunidade escolar. É fundamental a atuação da direção da escola que, necessariamente, deve ser dinâmica, aberta, voltada aos interesses da comunidade escolar e dos seus arredores. A relação precisa ser dialética, valorizando-se o respeito às observações e à participação de todos que vivenciam aquela realidade. $O$ poder do professor precisa ser legítimo perante os alunos, isto é, que a sua autoridade se insira "numa forma democrática de exercício do poder, na medida em que a obediência ocorra sem prejuízo da condição de sujeito daquele ou daqueles que obedecem" [...] "É essa educação, como prática democrática, que nos interessa" (PARO, 2008). Disciplina imposta não faz sentido.

Uma escola promotora de saúde oferece ambiente saudável, serviços de saúde e educação em saúde (OPAS, 1995). Todos os integrantes da comunidade escolar devem realizar esforços para consecução de seu objetivo principal que é formar cidadãos atuantes, responsáveis, comprometidos com a vida, com o bem estar coletivo, com a paz.

A educação em saúde deve fazer parte do dia a dia da escola, de forma contextualizada, para que os alunos possam crescer em conhecimentos, melhorar suas práticas e ter melhor qualidade de vida. Provavelmente o Ministério da Educação sugeriu temas transversais a serem trabalhados com os alunos das escolas brasileiras por todos os professores, de todas as disciplinas, visando a formação sadia do cidadão de bem. 
Os temas transversais se propõem a responder e a discutir questões atuais que têm impacto na sociedade, portanto podem ser modificadas conforme as alterações ocorridas na realidade social. Não devem se constituir em disciplinas isoladas, mas devem ser incorporadas no cotidiano escolar, perpassando todas as disciplinas e concretizando-se em práticas que reflitam a visão de mundo e o projeto pedagógico de cada unidade escolar. (SILVEIRA e PEREIRA, 2004)

$\mathrm{Na}$ visão dos alunos concluintes do ensino fundamental, apenas alguns professores, em aulas de algumas disciplinas, em momentos esporádicos, se referem a esses assuntos que deveriam permear todo o currículo , como a legislação prevê (MAINARDI, 2005).

São necessárias "estratégias inovadoras que venham atender às necessidades emergentes na dinâmica da sociedade moderna"... A escola, espaço privilegiado de formação, precisa estar pronta para dar respostas adequadas nesse sentido. No entanto, percebe-se claramente que os seus recursos humanos não estão completamente aptos para isso." (PELICIONI, 2000).

Como diz Freire (2002) "é na realidade mediatizadora, na consciência que dela tenhamos, educadores e povo que iremos buscar o conteúdo programático da educação. O momento desse buscar é o que inaugura o diálogo da educação como prática da liberdade. É o momento em que se realiza a investigação do que chamamos de universo temático do povo ou conjunto de seus temas geradores“.

O processo da educação é uma contínua construção.

Só ocorre aprendizagem e, portanto construção do conhecimento, quando o aluno se faz sujeito nesse processo, quando ele é ativo, participante, quando parte para a busca, quando quer aprender.

Pistrak e Freire tinham muito em comum; ambos procuraram encontrar na realidade existencial dos educandos as bases dialéticas para uma educação transformadora, libertadora. A realidade atual é, para os dois, o campo de estudos em torno do qual se deve desenvolver todo o processo ensino-aprendizagem. A compreensão crítica do mundo se constitui na base para o desenvolvimento de uma pedagogia social. (BLOEIZ JUNIOR, 2008 ).

Todo o fazer é social, plural. "O que eu faço é sempre parte de um fluxo social do fazer em que a condição prévia do meu fazer é o fazer (ou ter feito) dos outros, em que o fazer dos outros proporciona os meios do meu fazer" (HOLLOWAY, 2003 )

"Educar é prover situações ou experiências que estimulem a expressão potencial do homem e permitam a formação da consciência crítica e reflexiva. Implica 
em adesão voluntária. Assim, para que a educação se efetive, é preciso que o sujeito social motivado, incorpore os conhecimentos adquiridos, que a partir de então, se tornarão parte de sua vida e serão transferidos para a prática cotidiana" (PELICIONI, 2000)

$\mathrm{Na}$ verdade, o ideal seria que toda família tivesse conhecimentos e condições para educar seus filhos no dia-a-dia, desde a mais tenra idade, até mesmo desde o útero, tendo em vista a garantia da qualidade de vida; a vivência num ambiente saudável faria com que, automaticamente, o pequeno cidadão crescesse num meio propício à saúde e ao desenvolvimento máximo de suas potencialidades. Que entre os profissionais da educação houvesse mais união de esforços e menos competições descabidas, onde, muitas vezes, se vê técnicos tentando cercear e/ou controlar a autonomia de diretores de escola e/ou de professores, como se estes não fossem cabeças pensantes, como se também eles não tivessem feito estudos na área, como se o seu saber fosse de qualidade inferior, como se não fossem responsáveis por seus próprios atos. São justamente os que estão nas bases que conhecem mais de perto a realidade atual do processo ensino-aprendizagem; os que ocupam níveis superiores devem estar atentos para saberem ser apoio, saberem quando e como orientar se necessário, saberem participar juntamente com os demais, de mãos dadas e não contribuir para o emperrar do desenvolvimento de qualquer processo, como muitas vezes acontece.

Entretanto, sabe-se que muito disto está bastante distante da sociedade brasileira, por falta de interesse político, pela inexistência de políticas públicas, por falhas da própria sociedade que tudo aceita passivamente, outras vezes por falta de profissionalismo e comprometimento efetivo do educador e por uma série de outros motivos. Conforme dizia Paulo Freire, o futuro só vem, se a gente o fizer..se a gente o construir, transformando o presente.

Durante todo o século $X X$ o conceito de educação praticado na maioria das escolas tinha como razão principal a transmissão dos saberes produzidos pela humanidade, sendo que os alunos precisavam absorver os conteúdos sem qualquer questionamento, pois os mestres eram considerados detentores do saber.

Na pós-modernidade, nesse início do século XXI, acredita-se que o enfoque deva ser dado mais no aprender do que no ensinar; sabe-se que o objetivo maior é contribuir para a construção de cidadãos emancipados, responsáveis e que possam contribuir para uma melhor qualidade de vida própria e da sua comunidade. 


\section{REFERÊNCIAS}

ARSTEIN S.R. A ladder of participation American Institute of Planners Journal 35: 216-224, 1969.

BOLEIS JUNIOR, F. Pistrsk e Makarenko: uma pedagogia social e educação do trabalho Dissertação de Mestrado- São Paulo: Faculdade de Educação da USP, 2008.

\section{BRASIL. Constituição da República Federativa do Brasil , 1988.}

BRASIL. Lei Federal 8080/90 - Ministério da Saúde dispõe sobre as condições para a promoção, proteção e recuperação da saúde, a organização e funcionamento dos serviços correspondentes e dá outras providências.

BRASIL. Lei Federal 8142/90 - dispõe sobre a participação da comunidade na gestão do SUS e sobre as transferências intergovernamentais de recursos financeiros na área da saúde e dá outras providências.BRASIL- Ministério da Educação e do Desporto. Lei Federal 9294/96- Diretrizes e Bases da Educação Nacional. Brasília: Secretaria da Educação, Diário Oficial da União de 23 de dezembro de 1996.

BRASIL, Ministério da Educação e do Desporto. Parâmetros Curriculares Nacionais- Temas Transversais. Brasília: Secretaria de Educação Fundamental, 1998;.

BRASIL, Ministério da Saúde - Portaria 675/06 Carta dos Direitos dos Usuários da Saúde Brasília : Ministério da Saúde, 2006.

BRASIL. RIPSA- Rede Interagencial de Informações para a Saúde. http://www.ripsa.org.br/php/index.php

CASTRO, C.G.J e LEFEVRE A.M.C A Promoção de Saúde e o Planejamento Estratégico In Promoção de Saúde-a negação da negação . Rio de Janeiro: Vieira e Lent, 2004.

DIAS, J.C.P Problemas e possibilidades de participação comunitária no controle das grandes endemias Cadernos de Saúde Pública 14 (supl.b2): 19-37, 1998.

DIAS, R.B. Eu? Estou aí, compondo o mundo - uma experiência de controle de endemia,pesquisa e participação popular vivida em Cansanção, Minas Gerais Brasil Cadernos de Saúde Pública 14 (supl.2): 149-157.

FREIRE,P. Pedagogia da Autonomia São Paulo : Paz e Terra, 1997.

FREIRE, P. Pedagogia do oprimido São Paulo, Paz e Terra, 2002.

GOVERNO DE MINAS GERAIS - Pacto pela vida-Legislação, abr 2006.

HILSDORF, M.L.S História da Educação Brasileira: Leituras. São Paulo: Pioneira Thonsom Learning, 2003.

HOLLOWAY, J. Mudar o mundo sem tomar o poder. São Paulo : Viramundo, 2003. 
KLEIN, R The politics of participation in R Maxwell e N. Weaven Public Participatio in health king Edward's Fundation, London 17-32, 1984.

LEFEVRE ,F. e LEFEVRE A.M.C. Promoção de Saúde - a negação da negação Rio de Janeiro: Vieira e Lent, 2004.

LOURENÇO FILHO, M.B. Introdução ao estudo da escola nova São Paulo: Melhoramentos, 1978.

MAINARDI, N. A ingestão de Alimentos e as Orientações da Escola sobre Alimentação, sob o ponto de vista do aluno concluinte do Ensino Fundamental Dissertação de Mestrado - Escola Superior de Agricultura Luiz de QueirozUinversidade de São Paulo: Piracicaba, 2005.

MAINARDI, $\mathrm{N}$ e PEREIRA, I.M.T.B. - O exercício da cidadania na escola in $\mathbf{O}$ Mundo da Saúde São Paulo: 2007:jul/set 31(3): 434-437.

MAINARDI, N. e PIPITONE- Escolares Adolescentes:o que comem, o que observam, o que sugerem Piracicaba : Gera, 2007.

OPAS-Organización Mundial de la Salud "Promoción y educación de la salud escolar, una perspectiva integral: marco conceptual y operativo" Washington, 1995.

PARO, V.H Educação Como Exercício do Poder São Paulo: Cortez, 2008.

PELICIONI, M.C.F Educação em Saúde e Educação Ambiental - Estratégias de construção da Escola Promotora da Saúde Tese de Livre Docência São Paulo, Faculdade de Saúde Pública da USP, 2000.

PELICIONI, M.C.F. e PELICIONI, A . Educação e promoção da Saúde: uma retrospectiva histórica 0 Mundo da Saúde v 31 (3) p 320-328, São Paulo jul-set 2007.

PISTRAK, M. M. Fundamentos da Escola do Trabalho São Paulo: Expressão Popular, 2005.

SILVEIRA,G.T. e PEREIRA, I.M.T.B Escolas Promotoras de Saúde In: Lefèvre, F e Lefèvre A.M.C -Promoção de Saúde- a negação da negação. Rio de Janeiro: Vieira e Lent, 2004.

SOARES, M.L.A e SILVA, L.N - A década de 20, o advento da escola nova e o pensamento da igreja católica: o caso do manual Literaturas Estrangeiras - Revista Histedbr-on line Campinas, n 27, p 145 set 2007.

STONE L. Cultural influences in community participation in Health social science and medicine 35 (4) : 409-417, 1992.

VÁSQUEZ M.L. ET AL Nível de informação da população e utilização dos mecanismos institucionais de participação social em saúde em dois municípios do Nordeste do Brasil- Ciência e Saúde Coletiva vol. 10 supl 0 Rio de Janeiro set/dez 2005. 
VILLANUEVA, P.C Educar Evangelizando in Boletim Salesiano - Brasil-Ano 58 nำ mai/jun 2008.

VALLA V.V Participação popular e endemias : uma nova conjuntura Cadernos de Saúde Pública 14 (supl.2): 4-5 1998.

WALLERSTEIN, N. Powerless, empowerment and health: implications for health promotion programs. Journal of Health Promotion, Michigan,v.6, n.3, 1992.

WESTPHAL,M.F Promoção da Saúde e Prevenção de Doenças in Campos et al Tratado de Saúde Coletiva Rio de Janeiro e São Paulo: Editora Hucitec e Editora Fiocruz, 2006.

WESTPHAL,M.F. Promoção da Saúde e a Qualidade de Vida in Fernandez, J.C.A e Mendes, R (org) Promoção da Saúde e Gestão Local São Paulo: Hucitec, 2008.

WOELK, G.B Cultural and structural influences in the creation and participation in community health programmes Social Science and Medicine 35(4): 419-424, 1992.

ZACUS, D e LYSAC, C Revisiting community participation ealth Policy and Planning13(1)1-12,1997. 